\title{
Praktik Mindfulness bagi Orangtua dan Guru Siswa Sekolah Dasar SLB Negeri 2 Denpasar
}

\author{
Ni Made Ari Wilani*1, I Gusti Ayu Diah Fridari², Putu Nugrahaeni Widiasavitri ${ }^{3}$, I Komang Ari Mogi ${ }^{4}$ \\ 1,2,3,4Universitas Udayana \\ 1,2,3Program Studi Sarjana Psikologi, Fakultas Kedokteran, Universitas Udayana \\ ${ }^{4}$ Program Studi Ilmu Komputer, Fakultas MIPA, Universitas Udayana

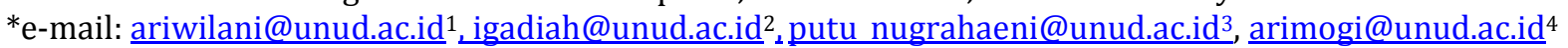

\begin{abstract}
Parents and teachers have their challenges in caring for deaf children. These challenges include often feeling tension or stress in parenting due to the difficulty of communicating with children, it takes a long time for parents to be able to accept the child's condition and the lack of knowledge parents have about the psychological development of children. These conditions, if left untreated, can make a negative impact on mental development not only of parents but also families. The psychological well-being of parents and teachers in caring for deaf children is crucial to improve. One treatment that can be considered is to provide mindfulness practice training. Mindfulness can increase the awareness of parents and teachers as well as enhance psychological well-being. Mindfulness training is given in the form of focus group activities. As a result, mindfulness training has a strong effect on providing parents and teachers new knowledge and skills about being aware of physical and psychological conditions and can better manage psychological well-being. The training needs to carry out continuously to enhance better results.
\end{abstract}

Keywords: parents, teachers, elementary school, deaf children, mindfulness training

\begin{abstract}
Abstrak
Orangtua dan guru memiliki tantangan dalam mengasuh anak tuna rungu. Tantangan tersebut antara lain seringnya merasakan ketegangan/stres dalam pengasuhan karena sulitnya berkomunikasi dengan anak, butuh waktu cukup lama bagi orangtua untuk bisa menerima kondisi anak serta kurangnya pengetahuan yang dimiliki orangtua tentang perkembangan psikologis anak. Kondisi tersebut bila dibiarkan berlarut-larut dapat membawa dampak negatif bagi perkembangan psikologis tidak hanya orangtua, tapi juga keluarga. Kesejahteraan psikologis orangtua maupun guru dalam mengasuh anak tuna rungu merupakan hal yang penting untuk ditingkatkan. Salah satu penanganan yang dapat dilakukan adalah dengan memberikan pelatihan praktik mindfulness. Mindfulness dapat meningkatkan kesadaran para orangtua maupun para guru serta meningkatkan kesejahteraan psikologis. Pelatihan mindfulness diberikan dalam bentuk aktivitas kelompok terfokus. Hasilnya pelatihan mindfulness memiliki efek yang kuat untuk memberikan pengetahuan dan keterampilan baru bagi orangtua dan guru tentang menyadari kondisi fisik dan psikologis dan dapat meningkatkan pengelolaan kesejahteraan psikologis dengan lebih baik. Pelatihan diharapkan dapat dilaksanakan secara berkesinambungan.
\end{abstract}

Kata kunci: orangtua, guru, SD SLB, anak tuna rungu, mindfulness

\section{PENDAHULUAN}

Seorang anak dikatakan mengalami tunarungu secara medis disebabkan oleh adanya kerusakan atau gangguan pada satu atau lebih organ pendengaran (Abdullah, 2013). Rusaknya organ pendengaran mengakibatkan ketidakmampuan dalam menjalankan fungsi menghantarkan dan memersepsi rangsang suara yang ditangkap untuk diubah menjadi rangsangan akustik. Anakanak yang mengalami tunarungu bukannya tidak dapat mendengar sama sekali, namun masih memiliki sedikit sisa kemampuan pendengaran (residual hearing).

Anak-anak tunarungu adalah anak-anak yang mengalami hambatan dalam kemampuan pendengaran yang memengaruhi kemampuan berkomunikasi secara keseluruhan. Hambatan dalam berkomunikasi yang dialami oleh anak tunarungu memengaruhi kemampuan untuk memahami dan mengucapkan bahasa secara oral (Hallahan, Kauffman, \& Cullen, 2009). Adanya hambatan berkomunikasi dengan orang lain mengakibatkan adanya hambatan dalam beberapa 
aspek belajar, terutama belajar secara verbal. Selain hambatan dalam aspek belajar, aspek sosial juga mengalami penyesuaian (Wasito, Sarwindah, \& Sulistiani, 2012).

Adapun karakteristik psikologis dan perilaku anak-anak yang mengalami tuna rungu secara umum menunjukkan perbedaan dibandingkan dengan anak normal. Ditinjau dari kekhasan perilaku, anak tuna rungu cenderung lebih lebih mementingkan diri sendiri, kalau marah mudah tantrum, cenderung lebih tergantung kepada orang lain, fokus perhatiannya cenderung lebih sulit untuk dialihkan, dan cenderung mengembangkan perasaan takut yang lebih besar (Sirait, Suriadireja, \& Sudiarna, 2016). Ditinjau dari perkembangan kognitif, anak-anak tunarungu secara umum tidak memiliki perbedaan potensi intelegensi dibandingkan dengan anak normal, namun hambatan dalam proses pemahaman dan abstraksi pengetahuan baru memengaruhi kemampuan belajar anak-anak secara keseluruhan. Dalam hal pencapaian akademik, sebagian besar anak-anak tunarungu mengalami hambatan dalam pencapaian prestasi akademik, terutama dalam hal membaca. Kondisi tersebut dapat membuat seorang anak mengulang kelas beberapa tahun hanya untuk lulus dalam kemampuan membaca (Hallahan et al., 2009). Anak-anak tuna rungu cenderung mengalami masalah dan menimbulkan tantangan dalam pengasuhan dan pengajaran yang dapat disebabkan oleh keterbatasan yang dimiliki.

Perkembangan anak tuna rungu sangat dipengaruhi oleh pengasuhan yang diterapkan oleh orangtua maupun figur-figur signifikan di lingkungan. Perkembangan yang baik dapat dicapai bila terdapat kerja sama yang selaras dan berkesinambungan antara pihak keluarga yang menerapkan pengasuhan di rumah dan para guru yang menerapkan pendidikan di sekolah (Ramadani, Redjeki, \& Mutadzakir, 2016). Kasih sayang yang diberikan dari orangtua kepada anak sangat berperan penting dalam perkembangan sosial anak, meningkatkan kemungkinan anak untuk berkompeten secara sosial dan menyesuaikan diri dengan lingkungan baru (Santrock, 2002). Pengasuhan yang tepat terhadap anak sangat memerlukan kepekaan dari orangtua untuk melihat tahapan perkembangan anak, mengenali kebutuhan unik tiap anak, serta memenuhi kebutuhan anak sesuai dengan tahapan perkembangan yang sesuai. Ada berbagai macam gaya pengasuhan yang dapat diterapkan oleh orangtua kepada anaknya, namun pengasuhan yang berbasis kesadaran (mindful parenting) dilaporkan merupakan salah satu alternatif gaya pengasuhan yang dapat meningkatkan kepuasan relasi dalam keluarga, kepuasan pengasuhan, kepuasan hidup, makna hidup untuk anak-anak berkebutuhan khusus salah satunya autisme (Conti, 2015). Penelitian lain terkait pengasuhan yang penuh kesadaran dan cinta kasih (compassionate and mindful parenting) dilaporkan dapat mengurangi stress dalam pengasuhan, meningkatkan kesejahteraan psikologis keluarga, dan meningkatkan kualitas hidup anak-anak dan keluarga (Cousineau, Hobbs, \& Arthur, 2019; Ying, 2016). Berdasarkan hasil-hasil penelitian yang telah dilakukan maka penerapan latihan dan praktik mindfulness dapat menjadi salah satu bentuk intervensi yang bertujuan untuk meningkatkan kualitas kesejahteraan psikologis para orangtua dan guru yang mengasuh dan mendidik anak-anak tuna rungu.

Hasil wawancara dan asesmen awal dengan orangtua siswa dan guru di SLB N 2 Denpasar menunjukkan bahwa orangtua jarang mendapatkan informasi dan pengetahuan mengenai perkembangan psikologis anak dan informasi mengenai pengasuhan berbasis kesadaran dan kasih sayang. Guru juga menginginkan tambahan pengetahuan mengenai pengasuhan terhadap anak-anak tuna rungu, dengan harapan dapat saling bersinergi dengan orangtua siswa. Menurut orangtua, pemberian informasi dan pelatihan mengenai pengasuhan sangat diperlukan untuk memperkaya wawasan dalam mendidik dan mengasuh anak. Hasil wawancara tersebut melatarbelakangi perlunya diadakan pelatihan mindfulness bagi orangtua dan guru untuk siswa sekolah dasar SLB N 2 Denpasar. Kegiatan pengabdian kepada masyarakat selama ini cukup banyak yang ditujukan kepada guru atau siswa, namun belum banyak yang menyentuh aspek orangtua, padahal orangtua dapat menjadi pemeran kunci bagi perkembangan anak-anak tuna rungu. Penerimaan positif dari orangtua kepada keterbatasan yang dimiliki anak tuna rungu menjadi pintu gerbang dalam menerapkan pengasuhan yang berbasis kesadaran dan cinta kasih. Solusi yang dapat diberikan terhadap masalah yang terjadi di SLB N 2 Denpasar adalah dengan mengadakan kegiatan praktik mindfulness bagi orangtua dan guru untuk meningkatkan 
kesejahteraan psikologis anak-anak tunarungu. Kegiatan dilakukan oleh beberapa orang psikolog sesuai dengan keahlian yang dimiliki.

Tujuan kegiatan pengabdian kepada masyarakat ini adalah memberikan informasi dan kesadaran pada pihak orangtua dan guru mengenai pentingnya menerapkan mindfulness dalam pengasuhan; memberi informasi mengenai penanganan terhadap masalah-masalah dalam pengasuhan anak tunarungu; serta memberikan pelatihan keterampilan mindfulness dalam mengasuh anak tunarungu kepada orangtua dan guru siswa sekolah dasar. Manfaat kegiatan pengabdian ini diharapkan agar pengetahuan dan kesadaran para orangtua mengenai penerapan mindfulness dalam pengasuhan untuk anak tunarungu semakin meningkat, pengetahuan mengenai perkembangan psikologis yang sehat dan pengasuhan yang hangat untuk anak tunarungu menjadi semakin berkembang, sebagai usaha pencegahan munculnya masalahmasalah psikologis di kemudian hari, dan sebagai usaha meningkatkan kesejahteraan psikologis orangtua, guru, maupun anak tuna rungu.

\section{METODE}

Kegiatan pengabdian kepada masyarakat dalam bentuk pelatihan praktik mindfulness bagi orangtua dan guru siswa sekolah dasar di SLB N 2 Denpasar dilaksanakan dalam satu kali kegiatan dalam satu hari. Sebelum pelaksanaan kegiatan, tim pengabdian dan guru telah bekerja sama untuk menyebarluaskan informasi kepada para orangtua dan guru yang tertarik untuk mengikuti kegiatan. Brosur dan poster kegiatan dibuat sebagai media informasi kegiatan dan dipasang di sekolah. Jumlah peserta pelatihan Mindfulness yang mendaftar kegiatan adalah berjumlah 88 orang, yang terdiri dari para guru dan orangtua siswa sekolah dasar, namun pada hari pelaksanaan kegiatan peserta yang hadir hanya 71 orang. Peserta yang ikut pelatihan terdiri dari 25 orang guru sekolah dan 46 orangtua siswa.

Kegiatan terdiri dari empat bentuk aktivitas yaitu pretes dan postes; psikoedukasi; praktik mindfulness, serta diskusi kelompok. Psikoedukasi yang diberikan adalah mengenai perkembangan anak tuna rungu secara umum, teori tentang pengasuhan, materi umum tentang mindfulness, dan materi tentang mindful parenting. Praktik mindfulness yang diberikan mengacu pada tuntunan mindfulness yang telah disiapkan sebelum kegiatan oleh seorang ahli psikologi transpersonal. Setelah praktik mindfulness selesai dilakukan, maka pemimpin kelompok melaksanakan diskusi kelompok dengan berfokus pada pengalaman selama praktik mindfulness, kendala yang dihadapi, dan efek segera yang dirasakan. Pra-tes dan pasca-tes menggunakan lembar self-report yang diisi oleh peserta sebelum dan setelah kegiatan (selesai diskusi kelompok). Pretes dan postes terdiri dari 7 aitem rating scale yang berkisar dari nilai 1 (paling rendah) sampai 7 (paling tinggi). Aitem pra-tes dan pasca-tes antara lain: kadar kebahagiaan yang dirasakan saat ini, kondisi fisik saat ini, kemampuan merasakan sakit di area tubuh tertentu, perasaan rileks, perasaan diri berharga, rasa mampu untuk mengendalikan diri, dan fokus perhatian. Selain pertanyaan spesifik, pertanyaan terbuka mengenai penyelenggaraan teknis kegiatan juga diberikan antara lain: manfaat yang didapat peserta dari kegiatan, kekurangan/ kelemahan kegiatan, serta harapan mengenai kegiatan yang serupa di masa depan.

Kegiatan dilaksanakan di dua ruangan berbeda yaitu ruang tari dan ruang guru karena keterbatasan daya tampung ruang serta mempertimbangkan kenyamanan kegiatan. Kegiatan dimulai pada pukul 8.00 Wita dan berakhir pada pukul 13.30 Wita. Di tiap ruang akan dipimpin oleh seorang psikolog dan seorang mahasiswa untuk menjadi fasilitator sekaligus pengamat kegiatan. Orangtua dan guru diacak sejumlah 15-16 orang tiap kelompok dan mendapat pelatihan selama 90 menit-100 menit. Terdapat dua kelompok yang mendapat pelatihan di ruang tari dan 3 kelompok di ruang guru. Setiap peserta mendapatkan materi pelatihan dan mengisi alat ukur kegiatan berupa pra-tes dan pasca-tes. 


\section{HASIL DAN PEMBAHASAN}

Kegiatan pengabdian kepada masyarakat dalam bentuk pelatihan praktik mindfulness bagi orangtua dan guru siswa sekolah dasar di SLB N 2 Denpasar telah dilaksanakan dengan baik. Orangtua siswa dan guru mengikuti kegiatan dengan antusias. Tidak ditemukan kendala yang bermakna selama pelaksanaan kegiatan. Semua peserta telah mengisi pretes dan postes sehingga pengolahan data lebih lanjut dapat dilakukan. Pada saat praktik mindfulness, secara kualitatif beberapa peserta mengalami pengalaman yang menarik. Latihan mindfulness hanya berlangsung selama 10 menit, namun beberapa peserta mengalami respon yang berbeda-beda. Ada beberapa peserta sampai tertidur sangat lelap, ada juga peserta yang tiba-tiba merasakan sakit di bagian tubuh tertentu, sebagian peserta merasakan kerinduan dan rasa sayang yang kuat kepada anakanak, ada peserta yang memunculkan memori dari peristiwa di masa lampau, ada juga peserta yang tidak merasakan hal-hal spesifik. Secara umum semua pengalaman peserta adalah wajar karena memang praktik menyadari diri dan tubuh (mindfulness) bisa berdampak pada peningkatan kemampuan mengobservasi diri sendiri sehingga seseorang yang menerapkan latihan mindfulness menjadi lebih peka dengan segala yang terjadi dalam diri sendiri termasuk konflik atau masalah di dalam diri (Pinazo \& Vazquez, 2014).

Pengolahan data secara kuantitatif juga dilakukan untuk dapat melihat efek kegiatan kepada para peserta. Pengolahan data dilakukan dengan bantuan SPSS. Pengujian normalitas data menunjukkan bahwa data memiliki distribusi normal. Berdasarkan pengujian statistik dapat diketahui bahwa rata-rata skor postes lebih tinggi dibandingkan rata-rata skor pra-tes. Data perbedaan rata-rata skor pretes dan pasca-tes dapat dilihat pada tabel.1.

Tabel 1. Beda Rata-rata skor pra-tes dan pasca-tes

\begin{tabular}{ccccc}
\hline Sumber Data & Mean & N & Standar deviasi & Std. Error Mean \\
\hline Pra-tes & 34.8169 & 71 & 9.40867 & 1.11660 \\
Pasca-tes & 40.8451 & 71 & 5.42915 & 0.64432 \\
\hline
\end{tabular}

Pengujian lanjutan perlu dilakukan untuk mengetahui apakah perbedaan rata-rata prates dan pasca-tes memang berbeda secara signifikan, maka perlu dilakukan pengujian dengan paired sample test. Hasil pengujian dengan paired sample test dapat dilihat pada tabel 2.

Tabel 2. Hasil Uji Paired Samples Test

\begin{tabular}{|c|c|c|c|c|c|c|c|c|}
\hline & \multirow[b]{2}{*}{ Mean } & \multirow{2}{*}{$\begin{array}{c}\text { Std. } \\
\text { Deviation }\end{array}$} & \multirow{2}{*}{$\begin{array}{c}\text { Std. Error } \\
\text { Mean }\end{array}$} & \multicolumn{2}{|c|}{$\begin{array}{l}\text { 95\% Confidence } \\
\text { Interval of the } \\
\text { Difference }\end{array}$} & \multirow[b]{2}{*}{$\mathrm{t}$} & \multirow[b]{2}{*}{$\mathrm{df}$} & \multirow{2}{*}{$\begin{array}{l}\text { Sig. (2- } \\
\text { tailed) }\end{array}$} \\
\hline & & & & Lower & Upper & & & \\
\hline $\begin{array}{l}\text { Pretes - } \\
\text { Postes }\end{array}$ & -6.02817 & 9.29819 & 1.10349 & -8.22901 & -3.82732 & -5.463 & 70 & .000 \\
\hline
\end{tabular}

Berdasarkan data yang disajikan di tabel 1 dan 2, dapat dilihat bahwa Berdasarkan data dari tabel 1 diketahui bahwa rata-rata skor pasca-tes lebih tinggi dibandingkan skor pra-tes. Perbedaan kedua hasil tersebut bersifat signifikan dilihat dari nilai signifikansi uji beda yaitu 0,00 $(\mathrm{p}<0,05)$ pada tabel 2. Maka dapat disimpulkan bahwa pelatihan praktik mindfulness meningkatkan aspek-aspek positif yang diukur selama pelatihan. Aspek yang diukur adalah kadar kebahagiaan yang dirasakan saat ini, kondisi fisik saat ini, kemampuan merasakan sakit di area tubuh tertentu, perasaan rileks, perasaan diri berharga, rasa mampu untuk mengendalikan diri, dan fokus perhatian. Besarnya efek pelatihan dihitung dengan menggunakan rumus size effect yang dikemukakan oleh Rosenthal (Field \& Hole, 2008). Gambar rumus perhitungan size effect dapat dilihat pada gambar 1. Perhitungan size effect menghasilkan angka 0,594, yang mengindikasikan bahwa pelatihan yang diberikan memiliki efek yang kuat. 


$$
r=\sqrt{\frac{\mathrm{t} 2}{\mathrm{t} 2+d f}}
$$

Gambar 1. Rumus menghitung size effect

Berdasarkan hasil analisis data yang dilakukan maka dapat ditarik kesimpulan bahwa pelatihan praktik mindfulness diberikan memberi dampak yang cukup signifikan terhadap beberapa aspek psikologis peserta yang diukur dalam pra-tes dan pasca-tes. Hasil evaluasi per aitem dalam pengukuran dapat diketahui bahwa setelah mengikuti kegiatan pelatihan, peserta secara subyektif merasa menjadi lebih bahagia, merasa lebih sehat, lebih mampu merasakan dan menyadari kondisi fisik, menjadi lebih tenang atau rileks, merasa lebih berharga atau berarti, menjadi lebih mampu untuk mengelola atau meregulasi diri sendiri, serta meningkatkan fokus perhatian. Hasil ini dapat dijelaskan bahwa praktik mindfulness dan disertai dengan belas kasih (compassion) mengajari seseorang untuk semakin menyadari kondisi internal diri, membantu seseorang secara sadar untuk menjadi lebih bahagia (Campos et al., 2016; Pinazo \& Vazquez, 2014).

Dalam konteks pengasuhan anak tuna rungu, stres psikologis yang dialami oleh orangtua dapat berdampak pada pola pengasuhan yang diterapkan kepada anak sekaligus memengaruhi perilaku anak yang cenderung maladaptif (Novitasari, 2016). Perilaku anak yang dianggap sulit makin membuat orangtua stres dan menimbulkan lingkaran siklus negatif dalam pengasuhan. Anak tuna rungu ketika berada dalam konteks pendidikan di sekolah memerlukan bantuan dalam menyesuaikan diri (Wasito et al., 2012). Anak tuna rungu membutuhkan selain membutuhkan pengajaran dari para guru, juga membutuhkan pengasuhan yang positif dari para guru karena guru juga membantu siswa untuk makin mandiri. Jika stres psikologis yang dialami oleh guru terlalu tinggi maka dalam memberikan pengajaran atau pendidikan juga tidak bisa optimal. Bagi guru yang mendidik anak-anak berusia muda, pelatihan dan pendampingan yang berkelanjutan dari pihak-pihak yang ahli diperlukan untuk mengembangkan siswa didiknya baik dalam aspek kognitif, perkembangan fisik, maupun sosial (Farida, Santi, \& Wibowo, 2019). Baik guru maupun orangtua memerlukan kondisi psikologis yang tenang, penuh kesadaran, dan positif agar bisa membangun relasi yang positif dengan anak tuna rungu. Dengan praktik mindfulness baik guru maupun orangtua dapat semakin menyadari kondisi psikologis (misalnya stres psikologis yang terlalu tinggi pada guru dan orangtua) yang sedang dialami sehingga bisa secara jernih dan sadar memutuskan tindakan yang tepat dibutuhkan dalam setiap kesempatan (Hölzel et al., 2011).

Berdasarkan hasil evaluasi kegiatan yang diisi oleh peserta, semua peserta menyatakan mendapatkan manfaat langsung dari praktik dalam pelatihan dan memberikan saran agar kegiatan dapat dilakukan secara berkelanjutan setiap tahun sehingga pengetahuan para orangtua terus meningkat. Salah satu dokumentasi kegiatan dapat dilihat pada gambar 2.

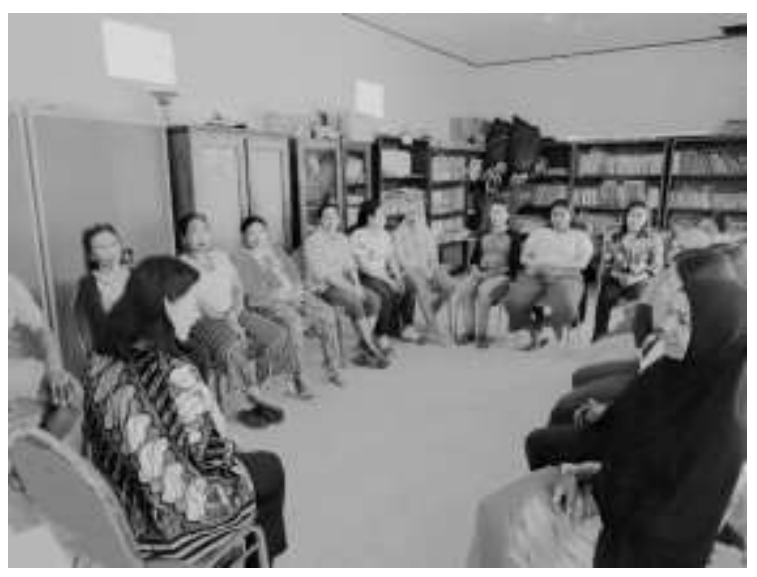

Gambar 2. Dokumentasi kegiatan 


\section{KESIMPULAN}

Kesimpulan yang didapatkan dari pelaksanaan kegiatan pengabdian kepada masyarakat ini antara lain:

1. Pelatihan praktik mindfulness dapat meningkatkan kesejahteraan psikologis orangtua dan guru siswa sekolah dasar SLBN 2 Denpasar.

2. Efek pelatihan praktik mindfulness berada pada kategori kuat.

3. Kegiatan yang menyasar orangtua dan guru seperti ini diharapkan dapat dilakukan secara berkesinambungan.

4. Kekurangan dalam pengumpulan data ini adalah tanpa adanya kelompok kontrol.

\section{UCAPAN TERIMA KASIH}

Penulis mengucapkan terima kasih kepada Lembaga Penelitian dan Pengabdian Kepada Masyarakat (LPPM) Universitas Udayana yang telah memberi dukungan pendanaan terhadap pelaksanaan kegiatan pengabdian kepada masyarakat.

\section{DAFTAR PUSTAKA}

Abdullah, N. (2013). Mengenal Anak Berkebutuhan Khusus. Magistra, 25(86), 1-10. Diambil dari http://garuda.ristekbrin.go.id/documents/detail/253246

Campos, D., Cebolla, A., Quero, S., Bretón-López, J., Botella, C., Soler, J., ... Baños, R. M. (2016). Meditation and happiness: Mindfulness and self-compassion may mediate the meditationhappiness relationship. Personality and Individual Differences, 93(June), 80-85. https://doi.org/10.1016/j.paid.2015.08.040

Conti, R. (2015). Compassionate Parenting as a Key to Satisfaction, Efficacy and Meaning Among Mothers of Children with Autism. Journal of Autism and Developmental Disorders, 45(7), 2008-2018. https://doi.org/10.1007/s10803-015-2360-6

Cousineau, T. M., Hobbs, L. M., \& Arthur, K. C. (2019). The Role of Compassion and Mindfulness in Building Parental Resilience When Caring for Children With Chronic Conditions: A Conceptual Model. Frontiers in Psychology, 10, 1-15. https://doi.org/10.3389/fpsyg.2019.01602

Farida, Y. E., Santi, A., \& Wibowo, D. D. (2019). Pendampingan Guru PAUD Ari-Ari Jepara Dalam Meningkatkan Pembelajaran PAUD Berbasis Budaya. Dinamisia : Jurnal Pengabdian Kepada Masyarakat, 3(1), 124-130. https://doi.org/10.31849/dinamisia.v3i1.2812

Field, A., \& Hole, G. (2008). How to Design and Report Experiments. Britain: Sage Publications.

Hallahan, D. P., Kauffman, J. M., \& Cullen, P. C. (2009). Exceptional Learners: An Introduction to Special Education, Eleventh Edition (Eleventh). USA: Pearson.

Hölzel, B., Lazar, S., Gard, T., Schuman-Olivier, Z., Vago, D., \& Ott, U. (2011). How Does Mindfulness Meditation Work? Proposing Mechanisms of Action From a Conceptual and Neural Perspective. Perspective on Psychological Science: a Journal of the Association for Psychological Science, 6(6), 537-559. https://doi.org/10.1177/1745691611419671

Novitasari, R. (2016). Kecenderungan Perilaku Disruptif Pada Anak Usia Prasekolah Ditinjau Dari Sres Pengasuhan Ibu. Intuisi, Jurnal Psikologi Ilmiah, 8(2), 61-70. Diambil dari https://journal.unnes.ac.id/nju/index.php/INTUISI/article/view/8597

Pinazo, D., \& Vazquez, C. (2014). The effect of meditation based on self-observation on cognitive responses in conflictive social interaction. Nordic Psychology, 66(3), 202-215. https://doi.org/10.1080/19012276.2014.935460

Ramadani, A., Redjeki, E., \& Mutadzakir, A. (2016). Kemitraan Orangtua Dan Lembaga Pendidikan Dalam Pengasuhan Anak Usia Dini Berkebutuhan Khusus. Jurnal Pendidikan Non Formal, 11(1), 20-28. https://doi.org/http://dx.doi.org/10.17977/um041v11i1p20-28

Santrock, J. W. (2002). Life Span Development: Perkembangan Masa Hidup (5, Jilid 1 ed.). Jakarta: Erlangga. 
Sirait, A. H., Suriadireja, P., \& Sudiarna, I. G. P. (2016). Kehidupan Penyandang Tuna Rungu (Studi Kasus Keluarga "KM" di Banjar Celuk, Kelurahan Panjer, Kecamatan Denpasar Selatan). Humanis, 17(1), 1-6. Diambil dari https://ojs.unud.ac.id/index.php/sastra/article/view/26450

Wasito, D. R., Sarwindah, D., \& Sulistiani, W. (2012). Penyesuaian Sosial Siswa Tuna Rungu di Sekolah Umum. Jurnal Psikologi Teori dan Terapan, 2(2), 81. https://doi.org/10.26740/jptt.v2n2.p81-92

Ying, M. (2016). Mindfulness, Compassion for Children and Parents Well Being. International Conference on Positive Psychology and Cignitive Behavioral Therapy, 42. https://doi.org/0.4172/2161-0487.C1.002 